\title{
El derecho de los contratos públicos en España: novedades y propuestas de futuro $\left.{ }^{*}\right)$
}

\author{
The law of public contracts in Spain: news and proposals for the future
}

\author{
José María Gimeno Feliu( ${ }^{(* *}$ \\ Universidad de Zaragoza (Zaragoza, España)
}

Resumen: Este trabajo da cuenta de la regulación de la contratación pública en España con ideas de prospectiva sobre cuál debe ser el futuro. Se presta atención a las principales líneas de la regulación española, y sus fines, para finalizar con unas conclusiones propositivas sobre la fundamentación regulatoria.

Palabras clave: Contratación pública en España - Contratación pública y estrategia Aspectos prácticos de las novedades de la regulación de contratos públicos en España - Futuro y retos de la contratación pública

\begin{abstract}
This paper gives an account of the regulation of public procurement in Spain with prospective ideas on what the future should be. Attention is paid to the main lines of Spanish regulation, and its aims, to end with some propositional conclusions on the regulatory rationale.
\end{abstract}

Keywords: Procurement in Spain - Public procurement and strategy - Practical aspects of new developments in the regulation of public procurement in Spain - Future and challenges of public procurement

(*) Nota del Editor: Este artículo fue recibido el 13 de marzo de 2021 y su publicación fue aprobada el 22 de marzo de 2021.

$\left(^{* *}\right.$ Catedrático de Derecho Administrativo de la Universidad de Zaragoza. Presidente del Tribunal Administrativo de Contratos Públicos de Aragón (desde el 11 de marzo de 2011 hasta el 03 de enero de 2018). Miembro del Comité Académico de Dirección de la Red Iberoamericana de Contratación Pública y miembro del Comité Científico del Osservatorio di diritto comunitario e nazionale sugli appalti publicci (Italia). ORCID: orcid.org/0000-0001-6760-9222. Correo electrónico: gimenof@unizar.es. 


\section{Evolución y contexto de la contratación pública en España. La influencia del derecho europeo}

La materia de contratación pública se ha convertido en una de las materias claves desde una perspectiva dogmática (directamente relacionada con las señas de identidad del Derecho administrativo) y la gestión práctica en tanto afecta a la correcta eficacia de importantes políticas públicas y tiene un claro impacto desde la perspectiva presupuestaria (o, si se prefiere, de sostenibilidad financiera) $)^{(1)}$. Esto explica que la contratación pública -y su fundamento- ha cambiado de forma muy notable en los últimos años. De una visión burocrática de la compra pública, diseñada desde una perspectiva hacendística y con escasa prospectiva se ha evolucionado hacia la idea la contratación pública como "herramienta jurídica al servicio de los poderes públicos para el cumplimiento efectivo de sus fines o sus políticas públicas"(2). Por ello la contratación pública (que supone el 22 por ciento de los presupuestos públicos según los últimos datos) debe ser re-contextualizada desde la perspectiva de inversión y no de gasto. $Y$ como inversión interesa su correcta articulación como actividad estratégica ${ }^{(3)}$.

Desde una lógica inicial de las primeras Directivas europeas en los años 70 basada en el objetivo de un mercado interior europeo, se ha evolucionado hacia una visión estratégica (e integral) de la contratación pública asentada en la idea del derecho a una buena administración: las Directivas 23, 24 y 25 de 2014, de 26 de febrero, respectivamente, "de cuarta generación"(4).

Nos encontramos en Europa y en España ante una nueva realidad jurídico-económica de la contratación pública, que exige una visión estratégica en un contexto económico globalizado. Una correcta utilización del contrato público, como instrumento al servicio de políticas pública, debe permitir reforzar los principios inherentes al modelo social europeo y garantizar su sostenibilidad en una situación geopolítica cada vez más tensionada desde los mercados orientales, que obligan a repensar y reforzar la estrategia del mercado interior europeo (Gimeno Feliu, 2014, p. 213). La contratación pública puede ser una palanca del cambio económico.

El Informe Especial del Tribunal de Cuentas Europeo número 10 de 2015, relativo a la necesidad de intensificar los esfuerzos para resolver los problemas de contratación pública que afectan al gasto de la UE en el ámbito de la cohesión, recuerda que la política de la Unión Europea en relación a la contratación pública constituye un pilar fundamental en relación a la consolidación del mercado interior y en torno a la consecución de una racionalización de los fondos públicos que garantice la sostenibilidad del sistema. La normativa europea de contratación pública ha pretendido desde sus inicios conseguir una correcta gestión de los fondos públicos optando por una delimitación objetiva: el contrato público. Es decir, existe una clara metodología jurídica de carácter funcional -y no formal- que obliga, a determinar si determinado ente es o no poder adjudicador y si un negocio jurídico es, o no un contrato público.

(1) Sobre el fundamento europeo y la nueva regulación española y sus aspectos prácticos véase, en extenso, a Gimeno Feliu, J. M. (2019). La Ley de Contratos del Sector Público 9/2017. Sus principales novedades, los problemas interpretativos y las posibles soluciones. Aranzadi.

(2) Las Instituciones europeas insisten en la visión estratégica de la contratación pública: "Comunicación de la Comisión "Europa 2020. Una estrategia para un crecimiento inteligente, sostenible e integrador". En esta línea se posiciona claramente, por cierto, el Consejo de la Unión Europea, en el documento "Conclusiones del Consejo: Inversión pública a través de la contratación pública: recuperación sostenible y reactivación de una economía de la UE resiliente” (2020/C 412I/01), en el que, tras hacer una prospectiva de la contratación pública insiste en la necesidad de su función estratégica.

(3) Véase Gimeno Feliu, J. (2020). La visión estratégica en la contratación pública en la LCSP: hacia una contratación socialmente responsable y de calidad. Revista Economía Industrial, 415, 89-97.

(4) Pero, además, no puede desconocerse la existencia de un derecho pretoriano que vertebra el sistema. En una materia tan sensible y a la vez tan cambiante, existe una importante "fuente de derecho", ya que la jurisprudencia del TJUE de la Unión Europea ha conformado un sólido y coherente derecho pretoriano, que sirve de fuente interpretativa y que limita aquellas opciones que puedan contravenir las reglas de la Unión Europea. De hecho, son, en la práctica, una especie de codificación, que dota de coherencia y seguridad jurídica al sistema (tanto a nivel comunitario como de aplicación práctica en los ordenamientos nacionales). Así, los conceptos "comunitarios" deben ser interpretados de conformidad con la doctrina fijada por el TJUE. Doctrina que debe ser conocida y respetada por los distintos intérpretes o aplicadores de las reglas de la contratación pública, lo que limita interpretaciones o prácticas nacionales que pretendan una visión "local" de las normas de contratos públicos. Véase Gimeno Feliu, J. (2015). La "codificación" de la contratación pública mediante el derecho pretoriano derivado de la jurisprudencia del TJUE. Revista Española de Derecho Administrativo, 172, 81-122. De especial interés véase el trabajo de Berberoff, D. (2018). La doctrina del Tribunal de Justicia de la Unión Europea en la contratación pública como condicionante interpretativo. En J. Gimeno Feliu (dir.), Estudio Sistemático de la Ley de Contratos del Sector Público (pp. 163-202). Aranzadi \& Cizur Menor. 
El derecho de la Unión Europea ha tenido, desde la entrada de España en las Comunidades Europeas en 1986, una influencia decisiva en el desarrollo y evolución de la normativa nacional sobre contratos públicos ${ }^{(5)}$. Y así se reconoce en la Exposición de Motivos de la LCSP de 2017 al recordar que su dependencia respecto del derecho de la Unión Europea, que extiende mucho más allá de la incorporación de las Directivas 23 y 24 de 2014.

Ello no siempre ha casado bien en España con nuestra tradición centrada en el contrato administrativo desde la perspectiva fundamentalmente subjetiva y del uso de prerrogativas públicas, heredera de los mimbres de la Ley de Contratos del Estado de 1965, cuya visión condiciono la evolución normativa posterior, pensada en clave formal y desde una estructura muy administrativizada. Lo que se tradujo en importantes condenas al Reino de España por la jurisprudencia del TJUE, que han obligado a incorporar los parámetros interpretativos funcionales utilizados sobre esta materia por el Derecho europeo. Y ello, como advierte la sentencia TJUE de 22 de diciembre de 2008, Magoora, C414/07, apartado 44, para alcanzar los resultados que el Derecho europeo persigue, dando prioridad a la interpretación de las normas nacionales que mejor se ajuste a dicha finalidad, para llegar así a una solución compatible con las disposiciones de dicha Directiva y dejando sin aplicación, de ser necesario, toda disposición contraria de la ley nacional. Es necesaria, en palabras de Alonso (2008), una interpretación de la norma nacional conforme al Derecho europeo (p. 395) (sin olvidar que existe reiterada jurisprudencia al respecto: en particular, las sentencias de 10 de abril de 1984, Von Colson y Kamann, apartado 26; de 5 de octubre de 2004, Pfeiffery otros, apartados 113 a 119 y la jurisprudencia allí citada, y de 4 de julio de 2006, Adeneler, apartados 108, 109 y 111) ${ }^{(6)}$.

Por otra parte, la contratación pública puede -y debe, insistimos- ser una técnica que permitiera conseguir objetivos sociales, ambientales o de investigación, en la convicción de que los mismos comportan una adecuada comprensión de cómo deben canalizarse los fondos públicos ${ }^{(7)}$. Se impone, pues, una visión estratégica de la contratación pública alejada de la rígida arquitectura del contrato administrativo y de planteamientos excesivamente burocráticos o formales (Gimeno Feliu, 2014, p. 18). Lo que exige, por otra parte, repensar (y previamente planificar) en como utilizar de la mejor manera los procedimientos y técnicas de la contratación pública $^{(8)}$.

A este fin se orienta, no sin incertidumbres, la Ley de Contratos del Sector Público de 2017, que, partiendo de los mimbres del Real Decreto Legislativo 3/2011, incorpora importantes novedades con la vocación de simplificar el procedimiento, reducir tiempos de adjudicación, mejorar el control de la adjudicación y la ejecución, incorporar una mayor transparencia y rendición de cuentas $y$, sobretodo, fomentar una nueva cultura de contratación pública ${ }^{(9)}$.

La LCSP pretende superar la tradicional inercia burocrática (y el mantra del "siempre se ha hecho así") para hacer la contratación pública un instrumento que permita una más eficaz, eficiente y colaborativa gestión de la contratación pública (lo que exige "innovación" en la práctica de la contratación pública ${ }^{(10)}$.

La nueva Ley de Contratos del Sector Público es, aun con sus "debilidades"

(5) Véase Meilan, J. (2015). Un meeting point de los ordenamientos jurídicos sobre contratación pública. Revista de Administración Pública, 198, 43-73.

(6) Véase Alonso García, R. (2008). La interpretación del Derecho de los Estados conforme al Derecho Comunitario: las exigencias y los límites de un nuevo criterio hermenéutico. Revista española de derecho europeo, 28, 385-410.

(7) Véase Moreno Molina, J. A. (2018). Hacia una compra pública responsable y sostenible. Novedades principales de la Ley de Contratos del Sector Público 9/2017, Tirant lo Blanch.

(8) Interesa destacar ya en este momento la importancia de la planificación, tanto de necesidades como de desarrollo del procedimiento de contratación. Al respecto, véase González García, J. (2018). Ley de Contratos del Sector Público y Entidades Locales: la exigencia de planificación de la contratación. Cuadernos de Derecho Local, 48, 247-264.

(9) Véase Moreno, J. (2018). Objetivos y novedades destacables de la Ley 9/2017 de contratos del sector público. Revista Gallega Administración Pública, 55, 311-327. Entre la literatura en España que aborda de forma integral los cambios normativos por la LCSP de 2017, en extenso, véase los libros colectivos Gimeno Feliu, J. (2018). Estudio Sistemático de la Ley de Contratos del Sector Público. Cizur Menor; véase Gamero, E. \& Gallego, I. (2018). Tratado de Contratos del Sector Público (vol 3). Tirant lo Blanch. Asimismo, véase Vázquez, F. \& Razquín, M. (2017). La adjudicación de contratos públicos en la nueva Ley de contratos del sector público. Editorial Aranzadi. Asimismo, véase Muñoz Machado, S. (2018). Contratos del Sector Público. Tomo XIII del Tratado de Derecho Administrativo y Derecho Público General. BOE. Finalmente, véase Mestre, J. \& Manent, L. (2018). La Ley de Contratos del Sector Público. Aspectos novedosos. Tirant lo Blanch.

(10) Sobre esta cuestión me remito al trabajo de García Jiménez, A. (2018). Las conexiones entre contratación administrativa e innovación. Tecnos. Este estudio (al que se le ha reconocido con el IV Premio de investigación internacional del Instituto García Oviedo) reflexiona sobre cómo deben adaptarse las Administraciones públicas a un nuevo modelo de gestión de la contratación pública. 
(fruto en parte de la decisión de "salvar" la regulación y sistemática existente que se deroga, frente a la opción de redactar un texto ex novo), un paso al frente para reconstruir las "murallas del Derecho Administrativo", concebido como garante del interés general al servicio de los ciudadanos (y de la necesaria transformación social). Desde este contexto la nueva Ley de Contratos del Sector Público es una "ventana de oportunidad" para un nuevo liderazgo institucional público a través de una adecuada articulación de la política de contratación pública que, además, puede ayudar en la estrategia de mejorar la productividad de nuestro modelo económico.

Para este objetivo, con este trabajo se pretende dar cuenta de las principales novedades y sus consecuencias prácticas en España, con la finalidad de favorecer una transición "no ruidosa" hacia esta nueva gobernanza de la contratación pública que supere la "presión política" de hacer más por menos y a corto plazo(11). Y de avanzar, por tanto, a una forma distinta de hacer contratación pública, que se cimiente en una adecuada planificación, la calidad de la prestación (y de su resultado), una eficaz cooperación interadministrativa, una innovadora visión del procedimiento en cuanto a su función y objetivos (donde la calidad es un paradigma irrenunciable) pensado en el mejor cumplimiento del fin público que es la causa del contrato. $\mathrm{Y}$, sobre todo, como hemos venido explicando desde hace tiempo, a una nueva cultura de la colaboración público-privada basada en la lógica del win/win y de la rendición de cuentas como herramientas al servicio de la buena administración.

\section{La Ley 9/2017 de Contratos del Sector Público en España: Su}

\section{estructura y principales novedades con impacto práctico en sus contenidos}

La transposición de las normas europeas en España se realiza mediante iniciativa legislativa ordinaria, es decir, mediante proyecto de Ley que prepara el Gobierno (opción que, por sí, "complica" el cumplimiento de los plazos previstos en las Directivas europeas) ${ }^{(12)}$. El texto aprobado (con un título excesivamente largo al citar a las Directivas que se transponen), que toma como punto de partida el vigente TRLCSP de 2011 (como consecuencia de esta decisión hay un "arrastre" de preceptos de la Ley derogada), "renuncia", tanto formal como materialmente, a la idea de un "Código de Contratos Públicos", con partes diferenciadas en función del objeto: contratos públicos, concesiones, contratos excluidos ${ }^{(13)}$. Se trata de un texto extenso y prolijo -son 347 artículos y 54 Disposiciones Adicionales (muchas de estas Disposiciones, en adecuada técnica normativa, deberían formar parte del articulado) y 16 Disposiciones Finales-. $\mathrm{Y}$ en ciertas ocasiones tiene un marcado carácter reglamentario que puede complicar la aplicación ${ }^{(14)}$. Desde esa perspectiva, como advierte Cano (2018), la regulación debe ser objeto de crítica. entre otros ${ }^{(15)}$.

La sistemática formal, como se ha explicado, no resulta innovadora, pues la

(11) Al respecto, me remito al estudio colectivo Gimeno Feliu, J., Tornos, J. \& Reig, M. (2019). La gobernanza de los contratos públicos en la colaboración público-privada. Cámara Comercio Barcelona \& Esade.

(12) Como primer antecedente legislativo de interés en España debe recordarse la Ley de Bases de 1963, germen del Texto Articulado de 1965. Y en su Exposición de Motivos ya se consideraba a la contratación pública como "un instrumento decisivo para el desenvolvimiento de la acción social", transformándose en "pieza maestra del nuevo estilo de operar administrativo"; al tiempo que se intentaba que el Estado contratase "siempre de la forma más ventajosa y segura". Sobre la evolución de la normativa de contratación pública en España me remito al trabajo de Colas, J. (2012). El itinerario de la contratación pública. De Cádiz a nuestros días. En E. Orduña \& V. Merino (coords.), Secretarios, interventores y tesoreros de la administración local: doscientos años al servicio de la ciudadanía (pp. 571-604). Aranzadi \& Cizur Menor.

(13) Véase Gimeno Feliu, J. (2011). La necesidad de un Código de Contratos Públicos en España. La contratación pública y las PYMES como estrategia de reactivación económica. En J. Gimeno Feliu (dir.) \& M. Bernal (coord.), Observatorio de los Contratos Públicos 2011 (pp. 25-84). Editorial Aranzadi.

(14) Sobre la estructura me remito al trabajo de Sanmartín, A. (2018). Estructura sistemática y distribución competencial. En J. Gimeno Feliu (dir.), Estudio Sistemático de la Ley de Contratos del Sector Público (pp. 203-232). Aranzadi Thomson Reuters. Asimismo, véase Valcárcel, P. (2018). Transposition of Directive 2014/24/EU in Spain: between EU demands and national peculiarities. En. M. Comba \& S. Treumer (edit.), EPLG Series Modernising Public Procurements: The Approach of Member States (vol. 8, pp. 232 y ss). Edward Elgar Publishing.

(15) Para ahondar más en este punto véase Cano, T. (2018). La nueva Ley de Contratos del Sector Público y las patologías del legislador: perspectiva general y principales novedades. Cuadernos de Derecho Local, 48, 15-19. Igualmente, crítico era ya, con relación a la "movilidad" de la normativa de contratación pública, el profesor Santamaría, J. (2013). La constante e interminable reforma de la normativa sobre contratación pública. Revista de Administración Pública, 159. 
opción adoptada es "respetar en lo posibles" la estructura del TRLCSP de 2011 (por eso se prevé una Ley de Contratación en sectores especiales) ${ }^{(16)}$. El articulado de esta Ley se ha estructurado en un Título preliminar dedicado a recoger las disposiciones generales en esta materia y cuatro Libros sucesivos, relativos a la configuración general de la contratación del sector público y los elementos estructurales de los contratos (Libro I), la preparación de los contratos administrativos, la selección del contratista y la adjudicación de estos contratos, así como los efectos, cumplimiento y extinción de estos contratos (Libro II), los contratos de otros entes del sector público (Libro III), y, por último, la organización administrativa para la gestión de la contratación (Libro IV) $)^{(17)}$. Este carácter extenso ha llevado a la doctrina (J. Baño, principalmente) a reflexionar sobre si la Ley cumple con su función de regulación o, por lo contrario, existe sobrerregulación ${ }^{(18)}$.

Es cierto que puede parecer un texto "continuista"(19). Sin embargo, existen notables diferencias, principalmente porque, tras el debate parlamentario, se han dado importantes pasos para intentar solucionar problemas estructurales de transparencia y de prevención de la corrupción, en especial derivados de la dualidad de regímenes jurídicos en función de la consideración o no de Administración pública, o de debilidad del control, lo que ponía en cuestión el objetivo inicial de impulsar una diferente "gestión práctica" de la contratación pública. Y pretende, además, un cumplimiento de las exigencias europeas, así como una reorientación de la contratación pública desde la perspectiva de estrategia para implementar políticas públicas.

Entre las novedades y ajustes técnicos efectuados se pueden referir como de especial interés los siguientes ${ }^{(20)}$ :

\subsection{El principio de integridad versus conductas corruptas o clientelares ${ }^{(21)}$}

Existen (y han existido) prácticas contrarias al principio de integridad, y su carácter "estructural" (de distinta "intensidad", y efectos, es cierto) en la gestión de los contratos públicos ${ }^{(22)}$. Prácticas que se encuentra muy

(16) Sobre la tramitación parlamentaria resulta de especial interés el estudio de Gonzalez García, J. (2018). La tramitación parlamentaria de la Ley de Contratos del Sector Público. Monografías de la Revista Aragonesa de Administración Pública, XVIII, 45-58.

(17) A juicio de Tejedor, la nueva Ley incurre en sobreregulación y complica de forma innecesaria la gestión pública. Véase Tejedor, J. (2018). La contratación pública en España ¿sobrerregulación o estrategia?. Civitas \& Cizur Menor. Esta misma opinión, desde otra perspectiva, es defendida por Cano Campos, al considerar a la LCSP una muestra de volatilidad, complejidad y falta de sistematicidad que caracteriza a la legislación administrativa de nuestro tiempo. Para ahondar en este punto, véase Cano, T. (2018). La nueva Ley de Contratos del Sector Público y las patologías del legislador: perspectiva general y principales novedades. Cuadernos de Derecho Local, 48, 12-67.

(18) Para ahondar más en este punto, véase Baño, J. (2018). La Ley de Contratos del Sector Público y gestión de lo público. ¿Regulación o sobrerregulación?. Monografías de la Revista Aragonesa de Administración Pública, XVIII, 11-20. Como contrapunto, hay que reseñar que el 1 de abril de 2019 ha entrado en vigor en Francia la nueva codificación de la actividad contractual del sector público mediante el Code de la Commande publique (publicado en el Journal Officiel de la République française ("JORF") el 5 de diciembre de 2018). Cuenta con 1747 artículos que reagrupan y sistematizan alrededor de 30 textos normativos empleados de manera cotidiana. Asimismo, incorpora las principales reglas de la materia creadas por vía jurisprudencial nacional y europea. Al respecto, resulta de interés la opinión de Vargas-Mazas, E. (2019, 1 de abril). La nueva codificación francesa de la contratación del sector público: el Code de la Commande publique. Observatorio de Contratación Pública. http://www.obcp.es/index.php/opiniones/la-nuevacodificacion-francesa-de-la-contratacion-del-sector-publico-el-code-de-la. También véase el trabajo de Gaudemet, Y. (2019). Le Code de la commande publique: un avènement, quelques questions. Revue des contrats, 1, p. 1.

(19) O un traje con las mismas rayas, en expresión para la anterior Ley, de Del Saz, S. (2007). La nueva Ley de Contratos del Sector Público ¿un nuevo traje con las mismas rayas?. Revista de Administración Pública, 174, 335-366.

(20) Con más profundidad me remito a Gimeno Feliu, J. (2019). La Ley de Contratos del Sector Público 9/2017. Sus principales novedades, los problemas interpretativos y las posibles soluciones. Aranzadi.

(21) Para ahondar más en este apartado, véase Cerrillo I Martínez, A. (2018). El principio de integridad en la contratación pública: mecanismos para la prevención de los conflictos de intereses y la lucha contra la corrupción. Aranzadi Thomson Reuters. La OCDE, en 2012 (Progress Made in Implementing the OECD. Recommendation on Enhancing Integrity in Public Procurement. París), ha propuesto un conjunto de normas y reglas de integridad, así como instrumentos para su análisis y evaluación.

(22) Véase Gimeno Feliu, J. (2016). La corrupción en la contratación pública. Propuestas para rearmar un modelo desde la perspectiva de la integridad. En M. Villoria, J. Gimeno, R. Jiménez \& J. Tejedor (dirs.), La corrupción en España. Ámbitos, causas y remedios jurídicos (pp. 247-300). Atelier. Asimismo, véase Gimeno Feliu, J. (2018). Corrupción y contratación pública. Las soluciones de la LCSP. En I. Gallego \& E. Gamero (coords.), Tratado de contratos del sector público (pp. 240-318). Tirant lo Blanch; véase Medina, T. (2016). La necesidad de reformar la legislación sobre contratación pública para luchar contra la corrupción: las obligaciones que nos llegan desde Europa. Revista Vasca de Administración Pública, 104(2), 77-113; y véase las reflexiones de Gonzalez Sanfiel, A. (2016). La integridad en la contratación pública: ¿un principio con sustantividad propia?. En F. Hernández (coord.), El impacto de la crisis económica en la contratación pública: España, Italia y Francia (pp. 31-53). Aranzadi Thomson Reuters. Finalmente, véase Martínez Fernández, J. (2017). Corrupción en la contratación pública. En A. Betancor (dir.), Corrupción, corrosión del Estado de Derecho (pp. 433-475). Civitas. 
vinculado a la ausencia de transparencia(23). Los efectos de la corrupción en la gestión administrativa son evidentes. Amén de una clara ineficiencia en la gestión de fondos públicos, es una pérdida de competencia que afecta a la solvencia cualitativa del sector empresarial. Sin una competencia real, la ejecución de obras, la adquisición de bienes o la prestación de servicios resulta más costosa para el erario público y deja al descubierto una importante desviación de recursos públicos ${ }^{(24)}$. En tiempos de crisis como los actuales son muchos más visibles estos efectos, que provocan una evidente desafección ciudadana(25). El objetivo de integridad - reconocido en la Convención de las Naciones Unidas contra la Corrupción- forma parte del derecho a una buena administración que se garantiza en el artículo 41 de la Carta de los derechos fundamentales de la Unión Europea (incorporada ya al ordenamiento español en virtud de la Ley Orgánica 1/2008, de 31 de julio). En ese sentido, nos acogemos a la definición de integridad de la OCDE (2015), en tanto menciona:

Integridad se refiere a que el uso de los fondos, los recursos, los activos y las autorizaciones es conforme a los objetivos oficiales inicialmente establecidos, y a que de dicho uso se informa adecuadamente, que es conforme al interés público y que está debidamente armonizado con los principios generales del buen gobierno (p. 6).

El artículo 1 LCSP incluye la referencia a este principio (aunque pasa un tanto desapercibido, lo que aconsejaría una redacción del artículo 1 distinta y "más didáctica"). No es una mera cuestión formal, pues amén del efecto didáctico de su inclusión, se refuerza la idea de que la integridad (la honradez), no es un simple principio ético, sino que tiene efectos jurídicos ${ }^{(26)}$. Y se adoptan medidas adecuadas a tal fin (aunque, de forma sorprendente, no se extiende la aplicación de la norma a partidos políticos y sindicatos y organizaciones profesionales cuando hay financiación pública mayoritaria, como era la opción inicial), con la intención de eliminar (o, al menos reconducir) prácticas que permitían la opacidad ${ }^{(27)}$.

\subsection{La "visión estratégica de la contratación pública" como nuevo paradigma}

La visión estratégica, tan importante para impulsar políticas de desarrollo sostenible, impulso a la innovación o consolidación de tejido empresarial de las PYMEs ${ }^{(28)}$, se ha convertido en el principal eje de la contratación, avanzando hacia una visión "más cercana" a la consideración del contrato público como inversión y no como gasto (superando la tradicional aplicación burocrática y economicista de los procedimientos de licitación pública en España).

El artículo 1.3 LCSP supone una clara "innovación" sobre la comprensión práctica de la contratación pública, renunciando a una filosofía burocrática formal y excesivamente economicista para incorporar, de forma preceptiva, la visión estratégica de la contratación pública, incluyendo referencias expresas al valor social y ambiental y la protección de las PYMES. Se abandona así una visión presupuestaria de la contratación pública, que se reorienta a una perspectiva instrumental de implementación de políticas públicas $^{(29)}$. En especial, se refuerza la posición de los trabajadores en los contratos,

(23) Klitgaard, R. (1994), define con una simple ecuación el gran problema de la corrupción: C= M + A - T. En ese sentido, C es Corrupción; M, Monopolio; A, Arbitrariedad y T, Transparencia. Cuanto menor sea la transparencia (entendida como rendición de cuentas), mayor resulta el índice de corrupción. Véase Klitgaard, R. E. (1988). Controlando la corrupción. Una indagación práctica para el gran problema del fin de siglo (p. 10). Sudamericana. Es decir, monopolio en la toma de decisiones, con una importante capacidad de discrecionalidad en la decisión, y ausencia o escasa necesidad de rendir cuentas, son los elementos que explican un mayor nivel de corrupción. Si se añade a esto, el dato de un marco normativo complejo (o disperso, o muy cambiante), como ya sucedido en urbanismo o contratación pública, es fácil entender el elevado índice de corrupción en España.

(24) Gimeno Feliu, J. (2019). Corrupción y seguridad jurídica. La necesidad de un marco normativo de las decisiones públicas anclado en los principios de Integridad y de Transparencia. Revista Internacional de transparencia e Integridad, 9.

(25) Véase Malaret, E. (2016). El nuevo reto de la contratación pública para afianzar la integridad y el control: reforzar el profesionalismo y la transparencia. Revista digital de Derecho Administrativo, 15, 21-60.

(26) Véase Gimeno Feliu, J. (2015). La reforma comunitaria en materia de contratos públicos y su incidencia en la legislación española. Una visión desde la perspectiva de la integridad. En Las nuevas directivas de contratación pública (ponencias sectoriales X Congreso Asociación Española Profesores de Derecho Administrativo) (pp. 37-105). Aranzadi \& Cizur Menor.

(27) Por todos, véase Gimeno Feliu, J. (2018). Ser o no ser poder adjudicador. ¡Esa no es la cuestión!. En J. Gimeno Feliu (dir.) \& C. de Guerrero (coord.), Observatorio de los Contratos Públicos 2017 (pp. 29-55). Aranzadi. Asimismo, véase Hernández Rodriguez, F. (2019). De nuevo sobre el concepto de poder adjudicador. Las entidades del sector público no administración pública. Revista Española de Derecho Administrativo, 198, 165-188.

(28) Véase Canals, D. (2018). Divisibilidad del objeto contractual y otras medidas legales de fomento de la participación de las pymes en la contratación pública. Cuadernos de Derecho Laboral, 48, 39-48.

(29) Se avanza, pues, en la cultura de la contratación socialmente responsable. Cuestión en la que ya se había venido trabajando desde el Foro de contratación socialmente responsable (http://www.conr.es). 
estableciendo obligaciones esenciales relativas a la calidad de las condiciones de empleo y de retribución, cuyo incumplimiento puede justificar la resolución del contrato. $Y$ se elimina la posibilidad de "dumping" social mediante precarización de condiciones laborales al establecer la obligación de respetar los convenios sectoriales.

Como complemento a esta visión estratégica de la contratación pública destaca también la previsión respecto a las especialidades de contratación pública en los servicios sanitarios, sociales y educativos dirigidos a las personas, lo que facilita una mejor respuesta jurídica a prestaciones alejadas a la lógica del mercado. Esto significa que un contrato de prestaciones personales de carácter sanitario o social podría estar excepcionado de las reglas de concurrencia propias de un contrato típico de servicios o productos, dado el marcado carácter estratégico, desde la perspectiva de correcta prestación, del mismo ${ }^{(30)}$. Se habilita que pueda existir un régimen no contractual para la prestación de estos servicios, así como que se diseñe un régimen singular de contratación ${ }^{(31)}$.

Desde esta nueva perspectiva estratégica hay que advertir de la incidencia de los artículos 131.2 145.1 LCSP, que indican que la adjudicación se realizará ordinariamente utilizando una pluralidad de criterios de adjudicación basados en el principio de mejor relación calidad-precio y desaparece la mención de la "oferta económicamente más ventajosa". Se utiliza, por tanto, el componente cualitativo de la prestación como elemento para decidir la oferta más ventajosa(32). El cambio es de gran relevancia y explica la nueva regulación del artículo
146 LCSP ya no incluya el concepto precio como concepto principal sino el de costes o rentabilidad, así como que se ponga en valor los servicios intelectuales (opción reclamada desde los servicios de ingeniería y arquitectura) ${ }^{(33)}$.

La mejor calidad en la prestación del contrato público (cuya causa, no se olvide, es el interés público) se interrelaciona claramente con la mejor eficiencia (y, en consecuencia, con la buena administración como derecho fundamental). Interesa, a estos efectos, recordar que desde el Derecho europeo de la contratación pública el precio no parece el elemento esencial para su configuración como contrato público. La exigencia de valorar la calidad/rentabilidad de un contrato público como nuevo eje decisional tiene importantes ventajas desde una perspectiva macroeconómica transversal, pues ha de permitir orientar determinados comportamientos de los agentes económicos intervinientes: quienes quieran acceder a los contratos públicos deberán cumplir necesariamente con las exigencias de calidad (en sus distintas funcionalidades) que determinen las entidades adjudicadoras. La calidad de la prestación es, por tanto, un elemento irrenunciable tanto en la

(30) Esta opción ha sido "validada" por las Sentencias TJUE de 11 de diciembre de 2014, CroceRossa Italiana y otros (asunto C-113/13) y de 28 de enero de 2016, CASTA y otros, Asunto C-50/14, que reconocen incluso la posibilidad de adjudicación directa.

(31) Véase Gimeno Feliu, J. (2015). Servicios de salud y reservas de participación ¿una nueva oportunidad para la mejora del SNS? (Análisis de los artículos 74 a 77 de la nueva Directiva 2014/24/UE sobre contratación pública). Revista Derecho y Salud, 26(2), 65-85. Véase, también, Gimeno Feliu, J. (2018). La colaboración público-privada en el ámbito de los servicios sociales y sanitarios dirigidos a las personas. Condicionantes europeos y constitucionales. Revista Aragonesa de Administración Pública, 52, 12-66. Asimismo, véase Bernal, M. (2018). La contratación de los servicios a las personas. En I. Gallego \& E. Gamero (coords.), Tratado de Contratos del Sector Público (vol. 3) (pp. 2841-2874). Tirant lo Blanch.

(32) La justificación de esta nueva visión de la contratación pública obliga a repensar la política de contratación pública, que debe atender a la correcta satisfacción de la necesidad que se pretende cumplir vía contrato público y donde, lógicamente, la mejor calidad debe ser un principio irrenunciable de la decisión a adoptar. Es más, conforma un elemento de lo que sería la correcta aplicación del principio de buena administración (por todas STJUE 28 de febrero de 2018, Vakakis kaiSynergates, que lo vincula a la diligencia). Difícilmente se puede considerar una decisión contractual como correcta desde la perspectiva de la buena administración cuando no se han tenido en cuenta los aspectos cualitativos de la prestación y el contrato.

(33) La exigencia de valorar la calidad/rentabilidad de un contrato público como nuevo eje decisional tiene importantes ventajas desde una perspectiva macroeconómica transversal, pues ha de permitir orientar determinados comportamientos de los agentes económicos intervinientes: quienes quieran acceder a los contratos públicos deberán cumplir necesariamente con las exigencias de calidad (en sus distintas funcionalidades) que determinen las entidades adjudicadoras. La calidad de la prestación es, por tanto, un elemento irrenunciable tanto en la planificación contractual como en la propia gestión del concreto contrato público. Pues, sin un estándar homogéneo de calidad, se rompe la regla de comparación de ofertas conforme a criterios de comparabilidad homogéneos, lo que quebraría el principio de igualdad de trato. La perspectiva de eficiencia debe ser siempre contextualizada en el concreto ámbito de la prestación que se demanda, pues las diferentes características del objeto pueden obligar a una solución jurídica distinta. Véase- con especial énfasis las páginas 102-112 de Gimeno Feliu, J. (2019). La Ley de Contratos del Sector Público 9/2017. Sus principales novedades, los problemas interpretativos y las posibles soluciones. Aranzandi.

(34) Interesa destacar ya en este momento la importancia de la planificación, tanto de necesidades como de desarrollo del procedimiento de contratación. Al respecto, véase González García, J. (2018). Ley de Contratos del Sector Público y Entidades Locales: la exigencia de planificación de la contratación. Cuadernos de Derecho Local, 48, 247-264. 
planificación contractual como en la propia gestión del concreto contrato público ${ }^{(34)}$. Pues, sin un estándar homogéneo de calidad, se rompe la regla de comparación de ofertas conforme a criterios de comparabilidad homogéneos, lo que quebraría el principio de igualdad de trato. La perspectiva de eficiencia debe ser siempre contextualizada en el concreto ámbito de la prestación que se demanda, pues las diferentes características del objeto pueden obligar a una solución jurídica distinta ${ }^{(35)}$.

Para cumplir este objetivo es necesario, además de un cambio de "cultura" (superar la "presión política" de hacer más por menos y a corto plazo), disponer de instrumentos flexibles y de uso sencillo que permitan a los poderes públicos adjudicar contratos transparentes y cualitativamente competitivos lo más fácilmente posible, en función de la mejor relación calidad/ precio (value for money), con la finalidad de "acabar con la práctica de comprar en función del precio más bajo" (W. Dening) $)^{(36)}$.

\subsection{La uniformidad jurídica para todo poder adjudicador} La principal novedad de la nueva regulación es que se decide la uniformidad de régimen jurídico, siendo indiferente el carácter o no de Administración pública del poder adjudicador para la aplicación de las reglas de contratación pública en los contratos de importe no a armonizado. Desaparece, pues la posibilidad de regulaciones "singulares" mediante Instrucciones internas propias en los procedimientos de importe no armonizado (estas solo quedan para entes del sector público que no sean poder adjudicador, artículo 321 LCSP, o los partidos políticos, sindicatos y organizaciones empresariales, ex artículo 3 LCSP).

Se pone fin a una "deslegalización procedimental" que resultaba distorsionadora desde la óptica del principio de seguridad jurídica, pues facilitaba la proliferación de distintos y variados procedimientos (distintos plazos, distinta documentación, etc.) que funcionaban como una barrera de entrada para los operadores económicos, a la vez que favorecían una fragmentación del mercado, la cual, a su vez, favorecía la aparición de prácticas de naturaleza clientelar, que impedían el efectivo funcionamiento - por inadecuada concurrencia- de las economías de escala. No hay nada más contrario a la efectividad del principio de transparencia que la dispersión normativa y el "caos" regulatorio de los distintos procedimientos de licitación ${ }^{(37)}$. De ahí que se pueda considerar esta uniformidad jurídica en las reglas procedimentales como la principal novedad del nuevo texto de contratos públicos.

Con esta uniformidad jurídica se corrige, a su vez, el problema de la dualidad jurisdiccional entre el orden civil y el contencioso-administrativo. Todas las fases de preparación y adjudicación, al margen de importe y naturaleza poder adjudicador, se residencian en el orden contenciosoadministrativo ${ }^{(38)}$. Existe ahora coherencia con la solución adoptada por el actual artículo 2 b) Ley de la Jurisdicción Contenciosoadministrativa de 1998, que establece la regla (que no debería ser alterada por la legislación de contratos, en tanto legislación sectorial), de que todas las cuestiones de preparación y adjudicación de cualquier poder

(35) Opción validada, sobre la base del principio de solidaridad, por la STJUE de 17 de junio 1997, Sodemare (asunto C-70/95), que admite excepciones al principio de libre competencia en el caso de contratos en el marco del sistema de la seguridad social en favor de entidades sin ánimo de lucro (apartado 32).

(36) La calidad en la prestación aconseja también estudiar la conveniencia de nuevos sistemas de retribución de los contratistas, como incentivos a una mejor ejecución. Así, por ejemplo, el sistema de retribución vinculado, en el ámbito sanitario al criterio de ValueBased Health Care (medir correctamente las cosas correctas), que supone abandonar el pago por Volumen o procedimiento (fee-forservice) por el modelo del "pago en salud por resultado conseguido", puede ayudar a conseguir una mejor calidad en prestaciones tan sensibles. Véase Gimeno Feliu, J. (2019). La compra pública de medicamentos: hacia el necesario equilibro entre calidad de la prestación asistencial y sostenibilidad financiera del sistema. Revista Española de Derecho administrativo, 202, 325-340.

(37) Sobre esta patología Gimeno Feliu, J.M. (2008). El nuevo ámbito subjetivo de aplicación de la Ley de Contratos del Sector Público: luces y sombras, Revista de Administración Pública, 176, 9-54 en la que he insistido en el estudio de Gimeno Feliu, J.M. (2016). La corrupción en la contratación pública. Propuestas para rearmar un modelo desde la perspectiva de la integridad. En M. Villoria, J. Gimeno, R. Jiménez \& J. Tejedor (dirs.), La corrupción en España. Ámbitos, causas y remedios jurídicos (pp. 258-262). Atelier. Igualmente, véase Noguera, B. (2015). La transparencia en la contratación pública: entre las reglas europeas y el ordenamiento jurídico español. En M. Rebollo, M. López \& E. Carbonell (coords.), Régimen jurídico básico de las Administraciones Públicas (pp. 937-958). lustel.

(38) No resulta posible una solución formal anclada en la idea rígida del contrato administrativo ya que el Derecho Administrativo se define en la actualidad no solo sobre la base del elemento subjetivo -Administración pública- sino también a partir de su consideración como Derecho exorbitante que se dirige a conciliar el interés general y el particular. Y resulta evidente tal condición en cualquier contrato público (donde las reglas y principios son públicos), tal y como ya advirtiera, por cierto, el Tribunal Supremo en la conocida sentencia Hotel Andalucía Palace (núm. 2113/1965 de 4 de febrero) donde el dato de que existen reglas administrativas es lo que decidió la competencia a favor del orden contencioso (en un contrato de una empresa pública). 
adjudicador se deben residenciar en sede contenciosa ${ }^{(39)}$. Es -y debe ser- el criterio funcional de poder adjudicador y no formal de Administración Pública, el que determina ante qué orden jurisdiccional se residencia la competencia ${ }^{(40)}$. Máxime cuando el artículo 2 LJ viene admitiendo la categoría de los actos "materialmente" administrativos.

En definitiva, en una actividad como la de los contratos públicos tan sensible desde una perspectiva económica, es necesario dotar a la arquitectura jurídica del control de la necesaria coherencia, que garantice el máximo de seguridad jurídica y favorezca la predictibilidad. Y, por cuanto resulta evidente que en la fase de preparación y adjudicación de cualquier contrato público (incluyendo las modificaciones ilegales), sea o no realizado por una Administración pública, hay un interés público relevante, debe corresponder a la jurisdicción contencioso-administrativa su fiscalización ${ }^{(41)}$.

\subsection{Depuración conceptual de los tipos contractuales desde la perspectiva europea}

En la tipología de contratos la LCSP de 2017 opta, a mi juicio correctamente, por un ajuste de definiciones de obras y servicios y se opta por el concepto funcional de obras: que exista influencia en la decisión final (STJUE 30 octubre 2009, Comisión/Alemania) y de concesión de obras y de concesión de servicios. Desaparece, por ello, el tipo contractual de servicios públicos. Lo que no impide un régimen jurídico "más intenso" en prestaciones de servicio público (lo que explica el régimen especial de servicios a las personas que contiene la Ley en el artículo 312 , que recoge el "régimen de servicio público" en estas actividades esenciales) ${ }^{(42)}$.

El artículo 29 LCSP regula los plazos de los contratos y opta por qué plazo el de contratos de servicios y concesiones sea común a todo poder adjudicador con excepciones justificadas (como el retorno de las inversiones, complejidad del servicio, entre otros) $)^{(43)}$. El plazo ordinario de duración de los contratos de servicios y concesión de servicios es de 5 años (porque es el que referencia la Directiva concesiones). Mediante la previsión de la Disposición Adicional 22, se mantiene la posibilidad de sociedad de economía mixta en tanto fórmula de CPPI, tanto para obras como servicios ${ }^{(44)}$. En todo caso, la opción de realizar CPP (desde de la perspectiva de SEC 2010) se encuentra en la regulación de concesiones, tanto de obras, como de servicios ${ }^{(45)}$. Se incorpora, por lo demás, una definición contrato servicios conforme al Derecho de la Unión Europea y la interpretación dada por el

(39) Al respecto, véase Mir, O. (2003). El concepto de Derecho Administrativo desde una perspectiva lingüística y constitucional. Revista de Administración Pública, 162, 47-87.

(40) Se explica de forma excelente en el trabajo de Valcárcel, P. \& Fernández, R. (2015). Reivindicación de la competencia del orden contencioso-administrativo para el control jurisdiccional de la contratación del sector público. En J. Gimeno (dir.) \& M. Bernal (coord.), Observatorio de los Contratos Públicos 2014 (pp. 237-277). Aranzadi \& Cizur Menor.

(41) Por otra parte, desde la lógica de la arquitectura de los principios procesales sobre los que se fija la competencia, básicamente sujetos y objeto, con causa de interés público, resulta incompresible que el criterio cuantía pueda determinar un cambio de orden jurisdiccional, posibilidad contraria al buen funcionamiento del Estado de Derecho y de la necesaria seguridad jurídica pues la dualidad jurisdiccional en asuntos de misma materia y sujetos quiebra los mismos.

(42) El modelo propuesto preserva las notas de garantía, continuidad y calidad de los servicios públicos, y la homogeneidad de tipo, en un contexto globalizado de la contratación pública, favorece una mejor interpretación y aplicación de los principios europeos de la contratación pública.

(43) Sobre el significado de la nueva regulación europea de la colaboración público-privada me remito a las páginas 57 hasta la 83 de Caamaño, F., Gimeno Feliú, J., Sala, P. \& Quinteros, G. (2017). Servicios públicos e ideología. El interés general en juego. Profit Editorial. Asimismo, véase Gimeno Feliu, J. (2018). El nuevo modelo concesional: hacia el necesario equilibrio entre lo público y lo privado. Las novedades de la Ley 9/2017, de Contratos del Sector Público. El Cronista del Estado Social y Democrático de Derecho, 74, 4-13.

(44) A favor de esta eliminación de contrato CPP del artículo 11 TRLCSP, véase -haciendo especial énfasis en las páginas 68-69Magide, M. (2012). El marco legal de la colaboración público-privada; algunas referencias particulares al ámbito de la defensa. En F. Laguna (coord.), El futuro de la colaboración del sector privado con el sector público (pp. 53-69). Editorial Centro de Estudios Ramón Areces \& Fundación Ramón Areces. Ciertamente, como bien ha sistematizado, en un análisis exhaustivo, son muchas las variables y complejidades de este tipo contractual "específicamente español" y, quizá, por ello convenga su eliminación para uniformizar las categorías y conceptos en un marco normativo europeo. Máxime, como indica María Hernando, en contratos de estas características, que aconsejan la mayor certeza del entramado jurídico y económico. Al respecto véase -enfatizando en las páginas 534-541- Hernando, M. (2012). La colaboración público privada. Fórmulas contractuales. Civitas. También véase Fernández, M. (2014). El necesario cambio de configuración del contrato de colaboración entre el sector público y el sector privado ante su escaso empleo en la práctica. REDA, 167, 293-326.

(45) Me remito a los siguientes trabajos publicados en el libro colectivo Amoedo-Souto, C. \& Gimeno Feliú, J.M. (2018). Estudio Sistemático de la Ley de Contratos del Sector Público, Aranzadi. Valcárcel, P. (2018). La delimitación de los tipos contractuales (pp. 431-451); Hernández, F. (2018). Delimitación de los contratos públicos de servicios y de concesión de servicios (pp. 477-516); Lazo, X. (2018). 
TJUE. Así, se incluye contrato concesión de servicios, que se caracteriza por la transferencia de un riesgo operacional. Ya no hay contrato de gestión de servicios públicos y se eliminan formalmente las figuras del concierto y de la gestión interesada (aunque la una se mantiene como contrato de servicios y la otra se engloba en el nuevo concepto de concesión). Interesa recordar que en la tipificación de una prestación como contrato de servicios o como contrato de concesión se exige, por exigencia de la jurisprudencia europea ${ }^{(46)}$, una interpretación funcional, corrigiendo prácticas que eludan la aplicación de las Directivas (STJUE de 29 de octubre de 2009 (Comisión/ Alemania))(47).

Se adopta el criterio del riesgo operacional (lo que no implica traspasar todo el riesgo, pero tampoco reconducirlo a la mera idea de riesgo y ventura) como elemento para delimitar concesión de contrato, lo que supone un cambio, pues bastara con que se transfiera el riesgo de suministro de oferta o el riesgo de suministro de demanda para que exista una concesión (criterio aplicable por igual a concesiones de obras o concesiones de servicio)(48). Se considerará que el concesionario asume un riesgo operacional cuando no esté garantizado que, en condiciones normales de funcionamiento, vaya a recuperar las inversiones realizadas ni a cubrir los costes que haya contraído para explotar las obras o los servicios que sean objeto de la concesión (lo que es compatible con pagos por disponibilidad) $)^{(49)}$.

La parte de los riesgos transferidos al concesionario supondrá una exposición real a las incertidumbres del mercado que implique que cualquier pérdida potencial estimada en que incurra el concesionario no es meramente nominal o desdeñable

Un riesgo operacional debe derivarse de factores que escapan al control de las partes. Los riesgos vinculados, por ejemplo, a la mala gestión, a los incumplimientos de contrato por parte del operador económico o a situaciones de fuerza mayor, no son determinantes a efectos de la clasificación como concesión, ya que tales riesgos son inherentes a cualquier tipo de contrato, tanto si es un contrato público como si es una concesión. Un riesgo operacional debe entenderse como el riesgo de exposición a las incertidumbres del mercado, que puede consistir en un riesgo de demanda o en un riesgo de suministro, o bien en un riesgo de demanda y suministro. Debe entenderse por «riesgo de demanda» el que se debe a la demanda real de las obras o servicios objeto del contrato. Debe entenderse por «riesgo de oferta» el relativo al suministro de las obras o servicios objeto del contrato, en particular el riesgo de que la prestación de los servicios no se ajuste a la demanda. A efectos de la evaluación del riesgo operacional, puede tomarse en consideración, de manera coherente y uniforme, el valor actual neto de todas las inversiones, costes e ingresos del concesionario" (considerando 20 de la Directiva 2014/23/UE del Parlamento Europeo y del Consejo)(50).

El riesgo operacional como elemento delimitador de los contratos de concesión (pp. 517-545); Tornos Mas, J. (2018). El contrato de concesión de servicios (pp. 1447-1484); y Lavilla, J. (2018). Régimen jurídico de la concesión de obras (pp. 1415-1445). También al trabajo de Huego, A. (2017). El riesgo operacional en la nueva Ley de Contratos del Sector Público. Documentación Administrativa, 4, 31-51.

(46) Sentencias del TJUE de 10 de septiembre de 2009, Wasser, 10 de marzo de 2011, Privater Rettungsdienst, y 10 de noviembre de 2011, Norma-A, SIA.

(47) Según esta doctrina consolidada, existirá un "contrato de servicios" en el sentido de las Directivas en un contrato mediante el cual un contratante, en virtud de las normas de Derecho público y de las cláusulas contractuales que regulan la prestación de estos servicios, no asume una parte significativa del riesgo que corre el poder adjudicador. Así, por ejemplo, el transporte de pacientes en ambulancias no será un contrato de gestión de servicios públicos sino de servicios, tal y como se advierte en la STJUE de 18 de diciembre de 2007 (Comisión/República Irlanda). Con matices a tal calificación puede verse la STJUE de 29 de abril de 2010 (Comisión/República de Alemania). En esta sentencia se recuerda que los servicios de transporte sanitario de urgencia o de transporte especial de enfermos, sobre los que versa el presente asunto, se incluyen a la vez en la categoría 2 o 3 del anexo I A de la Directiva 92/50 o del anexo II A de la Directiva 2004/18, y en la categoría 25 del anexo I B de la Directiva 92/50 o del anexo II B de la Directiva 2004/18, de modo que los contratos que tienen por objeto tales servicios están sujetos a la aplicación del artículo 10 de la Directiva 92/50 o del artículo 22 de la Directiva 2004/18 (véase, en este sentido, la sentencia de 24 de septiembre de 1998, Tögel, C-76/97, apartado 40).

(48) Por todos, véase Hernández, F. (2018). La nueva concesión de servicios. Estudio del riesgo operacional. Aranzadi. También véase Sahún, R. (2020). Riesgo operacional y servicio público. BOE. Finalmente, véase Peiro, A. (2019). El sistema de reparto de riesgos en las concesiones: hacia una nueva gobernanza. Aranzadi \& Cizur Menor.

(49) Existen problemas derivados de SEC 2010: ahora es transferencia de riesgo de demanda, o riesgo de oferta, o de ambo (son, pues, distinto a criterios de SEC 95). Sobre la incidencia del nuevo sistema de cómputo de déficit en SEC 2010, véase el trabajo de Macho, A. \& Marco, E. (2014). El impacto de las colaboraciones público-privadas en los niveles de déficit y deuda pública: análisis de los criterios de EUROSTAT. Revista de Administración Pública, 194, 437-474.

(50) Para determinar la existencia, o no, de riesgo operacional, debe tenerse en cuenta los criterios del TJUE sobre este asunto. Al respecto, véase el estudio de Huergo, A. (2018). Skin in the game: riesgo operacional y responsabilidad patrimonial administrativa. El Cronista del Estado Social y Democrático de Derecho, 74, 20-33. http://hdl.handle.net/10651/50947. 
Es preciso comprobar, por tanto, si el modo de remuneración acordado consiste en el derecho del prestador a explotar un servicio (u obra) e implica que éste asume el riesgo de explotación del servicio (u obra) en cuestión. Si bien este riesgo puede ser ciertamente muy limitado desde el primer momento, la calificación de concesión requiere no obstante que la entidad adjudicadora transfiera al concesionario la totalidad o, al menos, una parte significativa del riesgo que corre ${ }^{(51)}$. Obviamente, no resulta razonable exigir a la autoridad pública concedente transferir riesgos económicos superiores a las que existe en el sector de acuerdo con la normativa aplicable (sobre los que la entidad adjudicadora carece de margen de decisión) $)^{(52)}$.

El plazo concesiones queda vinculado al plazo necesario de retorno de las inversiones (como plazo ordinario, se fija el de cinco años que exige la Directiva de concesiones). Es decir, no hay discrecionalidad en la decisión del plazo concesional de tal manera que los plazos máximos que ofrece la LCSP no son de directa aplicación. El plazo es un elemento esencial, que debe ser ajustado al reparto de riesgos y que no puede favorecer de forma desproporcionada al concesionario por excesiva duración, pues -además de ayuda estatal ilegal conforme a las previsiones del artículo 107 TFUE- puede implicar una retribución indebida (en más) ${ }^{(53)}$.

La eliminación del tipo de contrato de gestión de servicios públicos no implica una involución desde la perspectiva de la mejor prestación de los servicios de interés general, pues en modo alguno se diluye el "régimen de servicio público", dado que las notas propias de regularidad, continuidad y equidad se pueden incluir tanto en el tipo de contrato de servicios como de concesión de servicios.

En todo caso, conviene insistir en que el debate sobre la forma de prestación de los servicios públicos, en sentido estricto, debe pivotar sobre la esencia de la propia idea y función del servicio público(54), es decir, la regularidad, continuidad y neutralidad en la prestación, garantizando la mejor calidad del servicio a los ciudadanos. No interesa tanto que sea gestión directa o indirecta como la mejor prestación (también en parámetros de eficiencia) de la actividad(55). Es decir, debe prevalecer la idea del nivel óptimo de gestión. El alcance sobre las fórmulas de colaboración público privadas y su función en la consecución del interés público, más allá de las personales posiciones ideológicas, exige una respuesta en clave jurídica, que concilie de forma adecuada los distintos principios e intereses en juego, y que preserve, en su decisión final, la esencia del derecho a una buena administración. Hay que evitar el maniqueísmo sobre quien presta mejor el interés general $y$, para ello, hay que garantizar el equilibrio entre lo público y lo privado y preservar, por supuesto, los principios de seguridad jurídica y de confianza legítima en inversiones de larga duración, que no son contrarios, sino complementarios, con los de control de la prestación y de adecuada regulación de los servicios públicos, de los que nunca podrá abdicar una Administración diligente.

En el régimen de contratos administrativos (para los poderes adjudicadores que tienen consideración de Administración pública) existen ajustes técnicos (por ejemplo, mayor plazo garantía en los contratos de obras), más importantes en la regulación de las

(51) EI TJUE ha admitido las peculiaridades que algunas prestaciones tienen, que la regulación puede limitar los riesgos, que la Administración contratante pueda estar atenta a las vicisitudes para reconocer que no se trata de un contrato de servicio. Así, por ejemplo, en la sentencia que resuelve el conflicto del servicio de abastecimiento de aguas en la comarca de Gotta (de 10 de septiembre de 2009, C-206/08) y en la que resuelve la cuestión prejudicial relativa a los contratos de transporte de asistencia médica y urgencias en Baviera (de 10 de marzo de 2011, C-274/09). Al respecto véase la página 235 de la literatura de Fuertes, M. (2013). Los riesgos del riesgo de explotación. En J. Gimeno, M. Bernal \& F. Vázquez (coords.), Observatorio de los Contratos Públicos (pp. 197-239). Aranzadi.

(52) Como bien advierte la STJUE de 10 de septiembre de 2009, Eurawasser, apartados 77 y 80 . El matiz es importante, pues solo así se consigue no desincentivar la iniciativa privada.

(53) Esta es una cuestión en la que la Directiva 2014/23 insiste, de tal manera que se fija un plazo orientativo de cinco años, que solo podrá ser mayor respetando la regla de que "la duración máxima de la concesión no podrá exceder el tiempo que se calcule razonable para que el concesionario recupere las inversiones realizadas para la explotación de las obras o servicios, junto con un rendimiento sobre el capital invertido, teniendo en cuenta las inversiones necesarias para alcanzar los objetivos contractuales específicos" (artículo 18)

(54) Concepto de servicio público de difícil delimitación conceptual, como ya ha advertido la Sentencia del Tribunal Constitucional núm.127/1994, de 5 de mayo, al afirmar que "la idea de servicio público no constituye una noción unívoca y sí un concepto muy debatido por la doctrina jurídica -con detractores y valedores-, sujeto a distintas elaboraciones y utilizado en diversos momentos históricos con finalidades también distintas".

(55) El contrato público y la concesión son herramientas para la mejor satisfacción de necesidades de la ciudanía, por lo que hay que preservar una gestión pública que preserve la idea del necesario equilibrio jurídico entre lo público y lo privado y la seguridad jurídica de las inversiones. 
concesiones, donde se incluye el concepto de la Tasa Interna de Rentabilidad o Retorno (TIR) como concepto a figurar en los pliegos de cláusulas administrativas particulares. Se confirma la actual regulación de la responsabilidad patrimonial administrativa en los casos de resolución de las concesiones (RPA), que es un elemento de seguridad importante, que funciona como efecto-llamada en los inversionistas al garantizar parte del negocio más allá del riesgo lógico de la gestión de la concesión ${ }^{(56)}$. La RPA se comporta como un elemento de aseguramiento de ciertos riesgos, pero no puede ser regulada o configurada de modo absoluto pues se diluiría el elemento del riesgo operacional(57).

Esta RPA se limita, para la resolución por causa imputable al concesionario, la RPA atendiendo al nuevo criterio SEC 2010 (el pago de la concesión se realizará atendiendo al valor de mercado de la misma) ${ }^{(58)}$. Si fuera resolución imputable a la Administración, la RPA desplegara sus efectos ordinarios: "la Administración abonará al concesionario el importe de la inversión realizada por razón de la expropiación de los terrenos y de la ejecución de las obras e instalaciones que, realizadas por éste, hayan de pasar a propiedad de aquélla, teniendo en cuenta su estado y el tiempo que restare para la reversión. La cantidad resultante se fijará dentro del plazo de seis meses, salvo que se estableciera otro en el pliego de cláusulas administrativas particulares"(59).

En palabras de Valcárcel (2018):

Este nuevo régimen también puede suponer un importante incentivo para la elaboración de cálculos más rigurosos de las inversiones necesarias en las concesiones. El hecho de que el concesionario ya no tenga garantizada la recuperación en cualquier caso de todas sus inversiones evitará o al menos dificultará, los ya referidos "elefantes blancos", así como también debería redundar en una gestión más diligente y mejor (p. 59).
Asimismo, interesa llamar la atención sobre el dato de que la retribución tendrá la condición de tarifa (y no de tasa), tanto en los casos de concesión de obras como de concesión de servicios (nuestros "servicios públicos")(60).

\subsection{Hacia una contratación pública más transparente}

Con la nueva LCSP se introduce más transparencia en los procedimientos, con exigencia de justificación y motivación de la necesidad y del procedimiento elegido (artículo 116.4 LCSP). Se exige, además, una detallada información que se debe publicar en los perfiles de contratante. Perfiles de contratante que, como indica el artículo 347 LCSP, deberán alojarse de manera obligatoria en la Plataforma de Contratación del Sector Público, gestionándose y difundiéndose exclusivamente a través de esta(61). En las páginas web institucionales de estos órganos se incluirá un enlace a su perfil de contratante situado en la Plataforma de Contratación del Sector Público (la publicidad en el Boletín oficial no es ya obligatorio y será gratuito) ${ }^{(62)}$.

Y lo que es más importante, desde la perspectiva de cumplimiento de esta obligación, es que el apartado 3 de este precepto obliga a que la publicación de anuncios y otra información relativa a los contratos en los perfiles de contratante surtirá los efectos previstos en la presente

(56) Un estudio completo y riguroso de la nueva regulación de la RPA se encuentra en el trabajo de Fernández Acevedo, R. (2017). En torno a la controvertida compatibilidad del concepto de concesión con la responsabilidad patrimonial de la Administración en caso de resolución. Ius Publicum. Network Review, 2, 1-38. http://www.ius-publicum.com/repository/uploads/27_11_2017_17_11Acevedo_2017.pdf

(57) Avala esta interpretación la nueva regulación del SEC (2010), aprobada por el Reglamento (UE) 549/2013 del Parlamento Europeo y del Consejo, de 21 de mayo de 2013, relativo al Sistema Europeo de Cuentas Nacionales y Regionales de la Unión Europea.

(58) En todo caso, se entenderá que es imputable al concesionario la resolución del contrato cuando ésta obedezca a haber sido declarado aquél en concurso o insolvencia en cualquier otro procedimiento.

(59) Artículo 271 del Real Decreto Legislativo 3/2011, de 14 de noviembre, por el que se aprueba el texto refundido de la Ley de Contratos del Sector Público.

(60) Véase Tornos, J. (2018). La tarifa como forma de retribución de los concesionarios de servicios de la Ley 9/2017, de Contratos del Sector Público. El Cronista del Estado Social y Democrático de Derecho, 74, 14-19.

(61) Conviene advertir que la finalidad de la Plataforma de Contratos del Sector Público debe servir para favorecer una adecuada publicidad y rendición de cuentas, pero no de monopolio de la contratación electrónica. En mi opinión, debe favorecerse la implantación de un sistema en competencia, homologado, de servicios electrónicos que permitan cumplir exigencias legales de utilización de medios electrónicos adaptándose a las necesidades y condiciones de cada poder adjudicador.

(62) La nueva redacción de la función del perfil de contratante ex artículo 63 LCSP indica claramente la vocación de estos para conseguir una efectiva transparencia y rendición de cuentas de la actividad contractual. Sobre esta nueva función del perfil de contratante, véase las sugerencias de García Jiménez, A. (2013). El perfil del comprador europeo: una forma de innovar en contratación pública. Revista de Administración Pública, 192, 381-400. 
Ley cuando los mismos estén alojados en la Plataforma de Contratación del Sector Público o en los servicios de información similares que se establezcan por las Comunidades Autónomas o las Ciudades Autónomas de Ceuta y Melilla. Y la no publicación en la Plataforma comportará la existencia de un vicio de nulidad de pleno derecho (supuesto regulado de forma expresa en el artículo 39.2 c) LCSP).

Existe, una novedosa regulación del procedimiento negociado con más detalle (artículos 164 a 169). Así, se advierte que existe obligación de negociar, delimitando la ponderación de los distintos aspectos a negociar (y la ausencia de negociación se considera causa de nulidad). Pero lo más destacado es que desaparece el supuesto de procedimiento negociado sin publicidad por la cuantía (con la evidente intención de evitar opacidad y los supuestos de corrupción). Opción que se explica de forma expresa en la Exposición de Motivos:

Con independencia de las normas llamadas a facilitar la lucha contra el fraude y la corrupción, se incluyen nuevas normas tendentes al fomento de la transparencia en los contratos. Así, debe mencionarse, entre otras cuestiones, la introducción de una novedad significativa: la supresión del supuesto de aplicación del procedimiento negociado sin publicidad por razón de cuantía.

Dicho procedimiento, muy utilizado en la práctica, resultaba muy ágil, pero adolecía de un déficit de transparencia, al carecer de publicidad, corriendo el riesgo de generar desigualdades entre licitadores. Para paliar estas deficiencias, se crea en la Ley un nuevo procedimiento de adjudicación, el denominado Procedimiento Abierto Simplificado, ya citado anteriormente al aludirse a los procedimientos de adjudicación, en el que el proceso de contratación está concebido para que su duración sea muy breve y la tramitación muy sencilla, pero sin descuidar, sin embargo, las necesarias publicidad y transparencia en el contrato.

El artículo 168 LCSP habilita un procedimiento negociado sin publicidad:

Cuando las obras, los suministros o los servicios solo puedan ser encomendados a un empresario determinado, por alguna de las siguientes razones: que el contrato tenga por objeto la creación o adquisición de una obra de arte o representación artística única no integrante del Patrimonio Histórico Español; que no exista competencia por razones técnicas; o que proceda la protección de derechos exclusivos, incluidos los derechos de propiedad intelectual e industrial.

La no existencia de competencia por razones técnicas y la protección de derechos exclusivos, incluidos los derechos de propiedad intelectual e industrial sólo se aplicarán cuando no exista una alternativa o sustituto razonable y cuando la ausencia de competencia no sea consecuencia de una configuración restrictiva de los requisitos y criterios para adjudicar el contrato.

Interesa destacar que ahora, con fundamento en el artículo 32 de la Directiva de contratación pública de 2014, se permite un procedimiento negociado sin publicidad cuando no exista alternativa o sustituto razonable o cuando exista de forma objetiva ausencia de competencia ${ }^{(63)}$.

Interesa destacar que el artículo 159 LCSP introduce el procedimiento abierto con tramitación simplificada. Los umbrales para su utilización son los no armonizados en suministros y servicios y 2 millones en obras. Este procedimiento, llamado a convertirse en el procedimiento ordinario en estos umbrales, sólo se podrá emplear si los criterios de adjudicación dependientes de juicios de valor no alcanzan determinado porcentaje de la valoración final y exige unos requisitos distintos pensados en la mayor rapidez como lo son la presentación de ofertas en el registro del órgano de contratación, la obligación del licitador de estar incluido en el registro de contratistas y declaración responsable de solvencia. Este procedimiento, contempla, además, en su apartado 6, una tramitación

(63) Este nuevo supuesto de procedimiento negociado sin publicidad y sin concurrencia ha sido admitido por la Sentencia del Tribunal Superior de Justicia de Cataluña 126/2016, de 9 de marzo, al recordar que es posible acepta que de acuerdo con la normativa comunitaria es posible acudir a la adjudicación directa como consecuencia de la existencia de derechos exclusivos, razones técnicas u bien económicas que impidan la concurrencia. Y esta tesis ha sido confirmada por el Tribunal Supremo con relación a la selección de la empresa Agbar para la constitución de la sociedad mixta para la prestación del servicio del agua en el área metropolitana de Barcelona. Así, la sentencia 1612/2019, de noviembre de 2019, en su fundamento undécimo afirma que "se puede concluir que concurre la justificación de la necesidad de otorgar el contrato a un empresario determinado, sin que existiera una alternativa o sustituto razonable, y sin que la ausencia de competencia sea el resultado de una restricción artificial de los parámetros de la adjudicación". En todo caso, como bien ha indicado Gallego (2014), "lo que se intenta evitar con este inciso es que la situación de exclusividad haya sido creada por el propio poder adjudicador con vistas al futuro procedimiento de contratación" (pp. 220-222). Obviamente, el procedimiento negociado sin publicidad conserva su carácter de procedimiento excepcional, en cuanto sólo puede ser empleados en supuestos muy concretos y de aplicación restrictiva, dado su carácter no competitivo. El recurso a este procedimiento debe ser objeto de justificación caso a caso [art. 84.1 f) de la Directiva de contratación pública]. Y la carga de la prueba de que existen realmente las circunstancias excepcionales que justifican la excepción incumben a quien quiera beneficiarse de ellas (entre otras, STJUE de 18 de mayo de 1995, Comisión/Italia, C-57/94). 
"sumaria" en importes inferiores a 80000 euros en obras y 60 000 euros en servicios. Con este procedimiento se ofrece un ámbito de aplicación más favorables a las PYMEs.

La transparencia se concreta también en que los criterios de adjudicación deben estar previamente determinados y ser objetivos. Al respecto, es leading case la doctrina fijada por la STJUE de 16 de septiembre de 2013 (Comisión contra Reino de España), aplicable con carácter general a cualquier procedimiento de licitación pública, al declarar que los criterios deben ser claros, favorecer la competencia y permitir que los licitadores puedan desplegar una adecuada estrategia en su oferta. Por ello, ponderación y sistema de asignación de la puntuación por cada criterio debe quedar reflejada de modo comprensible. Se trata, en definitiva, de prevenir la arbitrariedad de la decisión (STJUE de 2 de junio de 2016, Pippo Pizzo).

El régimen de mayor transparencia aparece también en la regulación de los modificados contractuales. El régimen de modificación del contrato (artículos 203 a 206 LCSP), que mantiene la distinción entre modificados convencionales y supuestos no previstos en el pliego, es más restrictivo que el que establecen las nuevas Directivas comunitarias, con la finalidad de evitar prácticas irregulares (no en vano el considerando 107 de la Directiva de contratación pública recuerda que es de directa aplicación la jurisprudencia europea sobre esta materia) ${ }^{(64)}$. En todo caso, la jurisprudencia del TJUE sobre esta materia sigue siendo de aplicación (considerando 107 de la Directiva 2014/24).

Interesa destacar que toda modificación debe publicarse (artículos 203.3 y 205 LCSP) y notificarse los acuerdos de modificación y que la modificación puede ser objeto de recurso especial. Esta regulación debe interpretarse conforme a los principios de la contratación pública $y$, para su correcto funcionamiento, parece conveniente, amén de avanzar en la idea de una adecuada planificación y gestión pausada del proyecto que posteriormente favorezca su rápida ejecución sin incidentes, que se regule mejor la responsabilidad de los autores de proyectos y directores de obras -exigiendo el replanteo previo antes de la aprobación del proyecto- y, en general, de todo personal responsable de la ejecución del proyecto.

\subsection{Nueva arquitectura del sistema de control previo vía recurso administrativo especial}

La LCSP mantiene la opción de ofrecer un recurso administrativo especial, potestativo y gratuito, que se resuelve por un órgano administrativo independiente, que viene a cumplir las exigencias de tutela de los licitadores en esta materia ${ }^{(65)}$. Con relación al recurso especial conviene reseñar la extensión del recurso especial a cuantías inferiores a las del importe armonizado europeo, es una decisión muy destacada, pues ha de ayudar corregir las debilidades detectadas de nuestro modelo de contratación pública ${ }^{(66)}$. El cambio producido es muy relevante pues implica superar la visión del recurso especial como una carga burocrática o "gasto" innecesario, para configurarse como un instrumento que permita garantiza la mejor transparencia mediante una estrategia del control preventivo que sea efectivamente útil, rápido, e independiente, vinculado al derecho a una buena administración y no a las prerrogativas de la Administración ${ }^{(67)}$. La opción de rebajar umbrales es, sin duda, un hito en la filosofía práctica de la contratación pública, y debe ser el inicio de un proceso para, tras dotar con medios y recursos a los órganos de recursos contractuales, extender al recurso especial a cualquier contrato al margen del importe(68).

Por ello, resulta muy relevante la opción de ampliar por el importe el recurso especial

(64) Meilin (2012) menciona: "La efectividad del principio de concurrencia exige una interpretación restrictiva a esta posibilidad -entendida como una potestad condicionada- en la que, en tanto parte del procedimiento de adjudicación, debería darse trámite de audiencia a todos los licitadores interesados en ese contrato, dando posibilidad a su impugnación en caso de entenderse incorrecta la modificación efectuada" (p. 143). Asimismo, véase las páginas 142-143 de Baño, J. (2013). Del ius variandi a la libre concurrencia: la prohibición de modificación como regla general de los contratos públicos. Anuario del Gobierno Local, 1, 141-151.

(65) El sistema diseñado por las Directiva 89/665 y 2007/66, pretende que exista un recurso rápido y eficaz, que exige independencia en su diseño. Sobre el fundamento del derecho europeo de recursos me remito por todos a Díez Sastre, S. (2012). La tutela de los licitadores en la adjudicación de contratos públicos. Marcial Pons.

(66) Debe recordarse que la Resolución del Parlamento Europeo, de 25 de octubre de 2011, sobre la modernización de la contratación pública (2011/2048(INI)), subraya que se debe evitar la introducción de nuevas normas para los mercados de contratación pública que no alcancen los umbrales de la UE, ya que se puede poner en peligro la seguridad jurídica establecida a escala nacional.

(67) Véase Gimeno Feliu, J. (2016). Observatorio de los contratos Públicos. Número monográfico especial (2016). Sistema de Control de la contratación pública en España. Aranzadi.

(68) Como bien ha destacado el profesor Baño, J. (2016) el sistema de recursos administrativos ordinarios no está configurado en clave de protección de la legalidad, pues pretende proteger a la Administración. De hecho, como bien explica, el sistema de justicia administrativa es un ejemplo de la inercia autoritaria del Derecho Público español. Por ello, como bien afirma, "la mejor alternativa 
frente a su limitación inicial a los contratos armonizados, que supera una extendida perspectiva de "gasto", y no de inversión, cuando se analizan los escenarios preventivos de control eficaz (vinculados a la buena administración)( ${ }^{(69)}$. El objeto del recurso especial incluye ahora las modificaciones y encargos ilegales (lo que supone que ya no es recurso precontractual). Las previsiones que contiene la LCSP sobre los supuestos de recurso deben tener carácter meramente enunciativo, dado que la Sentencia del Tribunal de Justicia de la Unión Europea de 5 de abril de 2017, (Marina del Mediterráneo SL y otros contra Agencia Pública de Puertos de Andalucía), ha fijado un criterio amplio de "decisión" a efectos del ámbito material del recurso especial(70).

Además, se mantiene el modelo de los tribunales administrativos (cuyas ventajas las ha destacado el profesor Santamaría Pastor ${ }^{(71)}$ ). Este sistema de "justicia administrativa especial" ha sido reforzado por el hecho de que el Tribunal de Justicia de la Unión Europea admitió a trámite la cuestión prejudicial presentada por el Tribunal Catalán de Contratos del Sector Público en fecha 23 de julio de 2014 (asunto C-203/14), lo que presupone reconocer que estos Tribunales administrativos -con fundamento en la Directiva $89 / 665$ y su reforma por Directiva 66/2007-, tienen la calificación de órganos jurisdiccionales por cuanto tienen origen legal, tienen carácter de permanentes, aplican un procedimiento contradictorio aplicando las normas jurídicas y son independientes (Sentencia de 17 de septiembre de 1997, asunto C-54/96 Dorsch Consult). $Y$ así se ha declarado por la sentencia TJUE de 6 de octubre de 2015, Consorci Sanitari del Maresme, C-203/14, que reconoce las notas exigidas para tal consideración -carácter contradictorio del procedimiento, independencia, y carácter obligatorio de su jurisdicción- y declara que los órganos de recursos contractuales de España son órgano jurisdiccional en el sentido del artículo 267 TFUE.

Por otra parte, se diseña un nuevo sistema de gobernanza, del que deriva tanto de un nuevo rol de la Junta Consultiva Contratación Pública (se crea un Comité con representación de las Comunidades Autónomas) por exigencia del Derecho de la Unión Europea ${ }^{(72)}$, como, principalmente, de la creación de un organismo independiente de supervisión y control es la bóveda de una nueva arquitectura institucional para promover las exigencias de gobernanza europea. La Oficina Independiente de Regulación y Supervisión de la Contratación está adscrita orgánicamente al Ministerio de Hacienda, pero formada por personal independiente (plazo de 6 años inamovibles), que asume las funciones de Gobernanza de las Directivas de contratación pública ${ }^{(73)}$. Podrá dictar instrucciones, pero no se le reconocen competencias de "anulación" o sanción ${ }^{(74)}$. Los poderes adjudicadores tendrán la obligación de transmitir el texto de los contratos celebrados referidos de forma que esta organismo podrá examinarlos y valorar si existen prácticas incorrectas -además de permitir a los interesados acceder a estos documentos, siempre que no resulten perjudicados intereses públicos o privados legítimos- lo que debe contribuir a reforzar la

al recurso administrativo es un buen recurso administrativo, entendiendo por tal el que garantiza una revisión de la actuación administrativa eficiente por un órgano funcionalmente independiente" (p. 669). Con esta ampliación del ámbito del recurso especial desde la perspectiva del importe se avanza en la filosofía del régimen equivalente en el nivel de eficacia exigido por STJUE de 6 de octubre de 2015, Orizzonte Salute, C-61/14.

(69) Véase Bernal Blay, M. (2013). El sistema de tutela de la buena administración contractual: balance de su implantación y propuestas para un mejor aprovechamiento. Revista Española de Derecho Administrativo, 160, 190-213.

(70) La Directiva de concesiones incorpora un supuesto tasado de causas de resolución anticipada cuyo no cumplimiento por una Administración o poder adjudicador abre la puerta al recurso especial.

(71) Véase, en especial las páginas 48-64, Santamaría, J. (2015). Los recursos especiales en materia de contratos del Sector Público. Aranzadi \& Cizur Menor.

(72) Cuestión en la que insiste la citada Recomendación de Decisión del Consejo de la Unión Europea de 27 de julio de 2016 , por la que se formula una advertencia a España para que adopte medidas dirigidas a la reducción del déficit.

(73) Tal como menciona Ponce (2017), la creación de este tipo de unidades no es sino una más de entre las distintas medidas posibles para luchar contra la corrupción, piezas de un puzzle complejo que configura el sistema de integridad de un Estado y condiciona su buen gobierno y buena administración (p. 8). Como advierte, este autor, la posible creación de oficinas de este tipo debe ser contextualizada en una estrategia global contra la mala administración y la corrupción y a favor del buen gobierno y la buena administración. La decisión sobre la creación de una oficina de este tipo debe ponderar, por exigencias del derecho a una buena administración, los costes y beneficios concretos, de todo tipo, que la misma pueda generar, y sólo crearla si los segundos superan a los primeros. Es preciso respetar los principios de buena regulación y la evaluación de impacto normativo exigido ahora por la ley $39 / 2015$.

(74) El funcionamiento de la OLAF en la Unión Europea puede servir de ejemplo para su puesta en funcionamiento. Sobre ello resulta interesante el trabajo de Fuertes López, M. (2014). La necesidad de un procedimiento para combatir el fraude (A propósito de las actuaciones de la Oficina europea de lucha contra el fraude, OLAF). Revista de Administración Pública, 195, 269-301. 
idea de integridad para prevenir supuestos de corrupción y/o clientelismo, que, a la vez que erosionan la idea de objetividad de las Administraciones públicas -que puede conducir a cuestionar su propia legitimidad democrática- conllevan claras y evidentes ineficiencias de los fondos pública. Esta Autoridad independiente se complementa con una Comisión Mixta con el Tribunal Cuentas, de seguimiento de la contratación pública ${ }^{(75)}$.

\section{Los retos de futuro de la contratación pública: Los ODS y la experiencia de la pandemia}

Los Objetivos de Desarrollo Sostenible de Naciones Unidas, agendados en el horizonte 2030 (aprobados el 25 de septiembre de 2015 y con vigencia desde enero de 2016), con la finalidad de promover la convergencia entre los países de la UE, en el seno de las sociedades y con el resto del mundo, han tenido una indudable repercusión en las agendas públicas de todos los poderes públicos. Los 17 objetivos, bajo el lema "Transformar Nuestro Mundo", presentan un carácter integrado e indivisible, que abarcan las esferas económica, social y ambiental (son una estrategia de futuro sumamente ambiciosa y transformativa). Agenda de Naciones Unidas que se propone, entre otros objetivos, el de un crecimiento económico sostenido, inclusivo y sostenible como algo esencial para lograr la prosperidad. Asimismo, la Agenda aborda los factores que generan violencia, inseguridad e injusticias, como las desigualdades, la corrupción, la mala gobernanza, entre otras ${ }^{(76)}$.

Los ODS tienen, más allá de su marcado carácter didáctico, una clara incidencia en cómo los poderes adjudicadores deben diseñar la arquitectura de su contratación pública. Así, la Unión Europea ha decidido incluir los Objetivos de
Desarrollo Sostenible en las políticas e iniciativas de la UE a todos los niveles, con el desarrollo sostenible como principio rector esencial de todas las políticas de la Comisión Europea. Idéntica estrategia de asumir como retos de primer orden los ODS se puede constatar entre los distintos poderes públicos españoles, que hacen de su mención una especie de mantra ideológico, cuando lo que interesa es sus consecuencias prácticas y su capacidad de transformación ${ }^{(77)}$.

Frente a posibles planteamientos que pivotan sobre el criterio precio frente al de valor, interesa recordar que el principio de eficiencia, inherente a la contratación pública, no puede ser interpretado desde modelos exclusivamente economicistas, sino que debe velarse por el adecuado estándar de calidad en la prestación del servicio ${ }^{(78)}$. Es decir, el principio de eficiencia se debe articular atendiendo a objetivos sociales, ambientales o de investigación, lo que redimensiona la visión estratégica de la contratación pública desde una perspectiva amplia del derecho a una buena administración.

Asimismo, transparencia, rendición de cuentas y justicia social son propios de la nueva arquitectura del contrato público en el contexto de desarrollo de los ODS, a modo de brújula ética ${ }^{(79)}$. En ese sentido, Gimeno (2014) señala que existe una brújula que señala como norte una visión estratégica y horizontal

(75) Sin duda puede ser una importante herramienta de apoyo a la función fiscalizadora del Tribunal de Cuentas (y sus homólogos autonómicos), con el fin de controlar legalidad y eficacia (que incluye la fase de ejecución) evitando un incorrecto uso de fondos públicos, independientemente de la personificación pública o privada que licite en tanto sea poder adjudicador. Véase Peña Ochoa, A. (2016). El nuevo rol de los organismos de control externo frente a la corrupción. En La corrupción en España: ámbitos, causas y remedios jurídicos (pp. 83-108). Atelier.

(76) Como es conocido estos retos se agrupan en cinco ejes: planeta, personas, prosperidad, paz y alianzas.

(77) Incluso con dimensión propia en la organización de la estructura de gobierno: Orden DSA/819/2020, de 3 de septiembre, por la que se regula la composición y funcionamiento del Consejo de Desarrollo Sostenible (creado por Orden PCI/169/2019, de 22 de febrero), que se concibe como un espacio ciudadano de carácter consultivo y de seguimiento de la implementación de la Agenda 2030 desde un enfoque participativo, incluyente y transparente. Porque la Agenda 2030 para el desarrollo sostenible, se presenta, ante todo, como un nuevo contrato social global y local que obliga a todos los actores sociales y a todas las Administraciones públicas a trabajar de forma coordinada.

(78) Sobre el significado de la eficiencia, y su no vinculación a una idea economicista de menor precio, me remito a Gimeno Feliu, J. (2016). Reglas básicas para mejorar la eficiencia y la transparencia en la contratación pública. Presupuesto y Gasto Público sobre Calidad institucional, transparencia y buen gobierno, 82, 137-158. También, véase Medina, T. (2013). Más allá del precio: las compras públicas con criterios de responsabilidad, Papeles de relaciones ecosociales y cambio global, 121, 87-97. Asimismo, véase Vaquer, M. (2011). El criterio de la eficiencia en el Derecho administrativo. Revista de Administración Pública, 186, 91-135. Finalmente, véase Fernández Acevedo, R. (2018). Los criterios de adjudicación de los contratos públicos. En I. Gallego \& E. Gamero (coords.), Tratado de Contratos del Sector Público (pp. 1387-1393). Tirant lo Blanch.

(79) Justicia social (que forma parte del artículo 1 de nuestra Carta Magna) y que se incardina dentro de los fines del artículo 9.2 de la Constitución española. Basta recordar como ya en 1944 la importante Declaración de Filadelfia (actual Carta de la Organización Internacional del Trabajo) declaró que un país no puede ser sostenible sin justicia social. 
de la contratación pública alejada de la rígida arquitectura del contrato administrativo y de planteamientos excesivamente burocráticos o formales y postulados economicistas (p. 18). Lo que exige, por otra parte, repensar (y previamente planificar) en cómo utilizar de la mejor manera los procedimientos y técnicas de la contratación pública para preservar la mejor calidad en la prestación de los "servicios públicos" desde esta lógica de los ODS, que son también brújula ética del sector privado. Frente a empresas que ponen el acento en una estricta visión mercantil que vincula el éxito al mayor beneficio, existen cada vez un mayor número de organizaciones empresariales que hacen de la responsabilidad social corporativa su principal identidad, fijando su éxito más allá de la lógica del mayor rendimiento económico (y sin atajos fiscales o de corrupción), vinculando su propia justificación al compromiso social, tal y como sucede con muchas empresas del tercer sector. Una sociedad que tenga clara la dirección ética debe reconocer y poner en valor esta forma de gestión empresarial, fomentando las relaciones con estas frente a empresas "especuladoras".

Por otra parte, el actual contexto de crisis económica derivada de la pandemia de 2020 refuerza la necesidad de avanzar hacia una nueva gestión económica mediante el contrato público que "piense en verde" y en "sostenibilidad social", no como exigencia estética, sino como herramienta generadora de valor ${ }^{(80)}$. Esta exigencia de sostenibilidad ambiental debe articularse en la priorización de los proyectos de infraestructuras a financiar, que deberán cumplir, en España, los objetivos de la Agenda Verde Europea y acomodarse a las directrices dictadas por las instituciones comunitarias (no puede olvidarse la exigencia de neutralidad climática). Desde esta perspectiva, parece oportuno que la norma legal a la que nos venimos refiriendo determine de forma clara los objetivos que se pretender fomentar, con la finalidad de dar seguridad jurídica a las propuestas de inversiones que se propongan: entre otros, proyectos que permitan descarbonizar la economía, para cumplir con los objetivos del Tratado de París, para luchar contra la degradación de la naturaleza y de los ecosistemas, para combatir la contaminación y para promover la economía circular.

En definitiva, las condiciones sociales y ecológicas son uno de los principales ejemplos de esta visión estratégica en la contratación pública claramente amparada por varios de los ODS. Y, en consecuencia, podemos ya afirmar que están admitidos y fomentados por las instituciones supranacionales, dado que la contratación pública no es un fin en sí misma, sino que es una "potestad" al servicio de otros fines de interés general (como son la estabilidad laboral, calidad ambiental, integración social) y que en modo alguno restringen o limitan la competencia, permitiendo dar efectividad a valores superiores actualmente recogidos en el TFUE. Así, como menciona el Tribunal de Justicia (Sala Segunda) en la sentencia de 30 de enero de 2020, Tim, C-395/18, se afirma: "Los operadores económicos deben cumplir, en la ejecución del contrato, las obligaciones en materia medioambiental, social y laboral, (...) un requisito de este tipo constituye, en la configuración general de la citada Directiva, un valor cardinal por cuyo respeto deben velar los Estados miembros" (apartado 38)(81).

La necesidad de reactivar un nuevo modelo económico (utilizando el contrato público) atendiendo a la lógica de los objetivos ODS, debe ser una oportunidad para avanzar hacia un nuevo modelo productivo más sostenible y más "inteligente". Corresponde a los poderes públicos liderar la nueva "cultura verde" que permita, desde la planificación, un nuevo escenario económico y social respetuoso con el medio ambiente. Los ODS son la oportunidad para relanzar este nuevo modelo de servicios públicos inteligentes y "circulares", que integren lo social, ambiental y la equidad como señas de identidad del modelo económico para conseguir un adecuado reequilibrio de riqueza y de derechos y deberes, para avanzar en una sociedad realmente inclusiva.

Para cumplir estos objetivos, más allá de apriorismos ideológicos, es necesario revisar e impulsar modelos de colaboración público-privada orientados a satisfacer el interés general. El ejemplo de muchas de muchas empresas en la crisis no puede ser cuestionado y su compromiso social debe ser la seña de identidad de un modelo

(80) En ese sentido, autores como Pernas, J. (2020) señalan -con acierto- que la implementación de políticas activas de economía circular puede suponer un beneficio económico neto de 1,8 billones de euros de aquí a 2030, la creación de más de un millón de nuevos puestos de trabajo antes del 2030" y, además, una notable reducción de emisiones de gases de efecto invernadero.

(81) Existe ya experiencias y guías sobre cómo introducir estos criterios. En la literatura más reciente destaca el libro de Pardo, M. \& Sánchez García, A. (2020). Inclusión de cláusulas sociales y medioambientales en los pliegos de contratos públicos. Aranzadi \& Cizur Menor. 
productivo cimentado en la mejor prestación de servicios o suministros a los ciudadanos ${ }^{(82)}$. Por ello, una correcta lectura de los ODS aconseja atender a la visión del Estado garante de servicios públicos de calidad, que ponga atención en la prestación regular, continua y neutra y no tanto en quien lo presta (que es, en esencia, el significado de la doctrina clásica del servicio público).

El objetivo de la transformación que pretende la Agenda de Naciones Unidas obliga a una actitud (y aptitud) proactiva, para aportar la mejor solución a las necesidades de la ciudadanía, necesidades que no son de simple ideología.

\section{Conclusiones propositivas}

La nueva regulación de los contratos públicos debe avanzar en la necesaria regeneración democrática y rediseño de la contratación pública como estrategia de liderazgo público que pivota sobre los principios de eficiencia, transparencia y buena administración. Por eso, más que nunca, necesitamos una contratación pública abierta, caracterizada por la mayor transparencia, la extensión práctica de los medios electrónicos como herramienta ineludible en la gestión de las decisiones públicas, la adecuada cooperación administrativa para desarrollar "economías de escala organizativas" y, por supuesto, una estrategia de profesionalización horizontal en la contratación pública, delimitando de forma adecuada los distintos roles y funciones en la gestión contractual. Las exigencias de eficiencia y de integridad en las decisiones públicas, como nuevos paradigmas del liderazgo institucional público, exigen la mejor transparencia en la contratación pública y, en consecuencia, la reducción a su mínima expresión de los espacios de opacidad o inmunidad, incompatibles con las exigencias de ética y ejemplaridad de nuestros tiempos.

Frente a inercias o dogmatismos, la situación "global" obliga a repensar soluciones jurídicas en la contratación pública que promuevan la eficacia de las políticas públicas y que concilien los interesen públicos en juego, diseñando procedimientos eficaces y eficientes (que importante las nuevas tecnologías, como los modelos blockchain) ${ }^{(83)}$, que pongan el acento en la calidad de la prestación y que eviten una indebida deslocalización empresarial(84).

En definitiva, necesitamos una nueva cultura de contratación pública: responsable, abierta, innovadora, cooperativa, profesionalizada, tecnológica y transformadora ${ }^{(85)}$. Una contratación pública estratégica y proactiva y no meramente reactiva, que ponga en valor la calidad de la prestación. Y, además, como advierte Hernández (2021), "debemos garantizar un régimen de contratación que permita dar respuesta a las apremiantes necesidades públicas y que actúe como dinamizador de un modelo económico más sostenible, inteligente y resiliente que nos prepare mejor para afrontar futuras crisis sanitarias, climáticas, alimentarias, tecnológicas o energéticas".

(82) Como señala Fracchia (2017), ante los casos de "egoísmo del mercado", lo que las Administraciones deben hacer es introducir obligaciones de servicio público. Público y privado en la gestión de los servicios públicos locales: entre externalización y municipalización (pp. 94-95). Este autor nos recuerda como en el dilema ente gestión pública y externalización el Consejo de Estado italiano (Dictamen 1075/2016, de 6 de abril) en la elección de la modalidad de gestión del servicio se decanta a favor del mercado. En la misma línea, Valcárcel, P. (2020). Works and service concession contracts: the way to boost PPP in Spain. En Piotr Bogdanowicz, R.Caranta \& Pedro Telles (edit.). Public-private partnerships and concessions in the EU: an unfinished legislative framework (vol. 1, pp. 168-188). Edward Elgar Publishing.

(83) Sobre esta cuestión es un referente en España el profesor Bernal Blay. Véase su opinión en Bernal Blay, M. (2020). Blockchain Administración y contratación pública. Observatorio de Contratación Pública. http://www.obcp.es/opiniones/blockchain-administraciony-contratacion-publica. Sobre esta cuestión interesa igualmente la opinión de Valero. Al respecto, véase Valero, J. (2020). Inteligencia Artificial y contratación del sector público. Observatorio de Contratación Pública. http://www.obcp.es/opiniones/inteligencia-artificialy-contratacion-del-sector-publico.

(84) Así lo advierte, por lo demás, la Comisión europea en su Comunicación sobre Directrices sobre la participación de licitadores y bienes de terceros países en el mercado de contratación pública de la UE -Bruselas, de 24 de julio de 2019. C (2019) 5494 finalHay que recordar igualmente la importante Comunicación de la Comisión europea Conseguir que la contratación pública funcione en Europa y para Europa. Estrasburgo, 3 de noviembre de 2017 COM (2017) 572 final.

(85) En definitiva, la administración electrónica debe servir, asumiendo el importante rol de las nuevas tecnologías disruptivas, para mejorar la transparencia y la eficiencia (social) en la contratación pública, cuya transversalidad o carácter de política pública horizontal es cada vez más evidente. Sobre los diferentes roles del principio de transparencia, véase Valcárcel, P. (2019). Tres dimensiones de la transparencia en la contratación pública. Rendición de cuentas, respeto de los derechos de operadores económicos y mejora global de la gestión de este sector a través del "big data". En J. Gimeno (dir.) \& C. de Guerrero (coord.), Observatorio de contratos públicos 2018 (pp. 93-130). Aranzadi Thomson Reuters. 
Una última reflexión. Desde una correcta aplicación del derecho a una buena administración no pueden desconocerse las exigencias de "justicia social" sobre las que se cimientan los ODS, que deben ser el impulso para rearmar un modelo de crecimiento sostenible, que integre lo social, ambiental y la equidad como señas de identidad del modelo económico para conseguir un adecuado reequilibrio de riqueza y de derechos y deberes, para avanzar en una sociedad realmente inclusiva. Lo que exige, además de la necesaria convicción, planificación, una verdadera estrategia de objetivos realizables a medio y largo plazo (frente a la improvisación) y una visión no meramente "numérica e insensible" sobre los resultados. Como bien advirtió la Abogado General J. Kokott en un procedimiento judicial en la Unión Europea, "Aunque el sabor del azúcar, en sentido estricto, no es diferente en función de si ha sido adquirido de forma justa o injusta, un producto que ha llegado al mercado en condiciones injustas deja un regusto más amargo en el paladar de los clientes conscientes de la responsabilidad social". Educar el paladar de instituciones públicas y privadas y de los ciudadanos en el significado y alcance de los ODS, para que pongan en valor la sostenibilidad social, es el gran reto para poder consolidar un Estado de Derecho que puede enarbolar como principal bandera la de la justicia social, objetivo fundamental del derecho a la buena administración en el siglo XXI.

Y es que los ODS, en una dimensión funcional, pueden ser el instrumento para reconstruir las murallas del Derecho público, concebido como garante del interés general al servicio de los ciudadanos (y de la necesaria transformación social)(86). Lo que puede ayudar a corregir el actual gap entre ciudanía e instituciones públicas y para asentar el modelo institucional cimentado sobre el buen gobierno. La idea de buen gobierno va más allá de la ausencia de corrupción. Se refiere a unas instituciones transparentes, objetivas y con reglas predecibles para todos, que favorezcan la necesaria seguridad jurídica para que pueda emerger "una economía sana y competitiva". Desde este contexto los ODS, que deben facilitar la articulación armónica los denominados círculos de excelencia -excelencia de servicios (pensar primero en las personas), excelencia de procesos (hacer lo que toca sin burocracia indebida) y excelencia técnica (tener talento y conocimiento)-, son una "ventana de oportunidad" para un nuevo liderazgo institucional público a través de una adecuada articulación de la política de contratación pública que, además, puede ayudar en la estrategia de mejorar la productividad de nuestro modelo económico y, principalmente, servir de "política palanca" para proteger con eficacia los derechos sociales.

\section{Referencias bibliográficas}

Alonso, R. (2008). La interpretación del Derecho de los Estados conforme al Derecho Comunitario: las exigencias y los límites de un nuevo criterio hermenéutico. Revista española de derecho europeo, 28, 385-410. http://www.revistasmarcialpons.es/ revistaespanoladerechoeuropeo/article/view/414

Baño, J. (2016). El recurso administrativo como ejemplo de la inercia autoritaria del Derecho Público español. En F. López (coord.), Las vías administrativas de recurso a debate (pp. 496-518). Instituto Nacional de Administración Pública.

Directiva 2014/23/UE, de 26 de febrero de 2014 , relativa a la adjudicación de contratos de concesión. Diario Oficial de la Unión Europea, 94/1, 28 de marzo de 2014. https:// eur-lex.europa.eu/legal-content/ES/TXT/ PDF/?uri=CELEX:32014L0023\&from=it

Fracchia, F. (2017). Público y privado en la gestión de los servicios públicos locales entre externalización y remunicipalización. En T. Font \& J. Díez (coords.), Los servicios públicos locales. Remunicipalización y nivel óptimo de gestión (pp. 80-116). lustel.

Gallego, I. (2014). Los procedimientos de adjudicación en la nueva Directiva sobre contratación pública. En J. Gimeno \& M. Bernal (coords.), Observatorio de los Contratos Públicos 2013 (pp. 165-232). Aranzadi \& Cizur Menor.

Gimeno Feliu, J. (2014). El nuevo paquete legislativo comunitario sobre contratación pública. De la burocracia a la estrategia: (el contrato público como herramienta del liderazgo institucional de los poderes públicos). Aranzadi \& Cizur Menor.

Hernández, F. (2021). Una ley de contratos para tiempos de crisis. Observatorio de Contratación Pública. http://www.obcp.es/opiniones/una-ley-decontratos-para-tiempos-de-crisis

Organización para la Cooperación y el Desarrollo Económico - OCDE (2015). Recomendación del Consejo sobre contratación pública. OCDE.https:// www.oecd.org/gov/ethics/OCDE-Recomendacionsobre-Contratacion-Publica-ES.pdf

Pernas, J. (2020, 6 de abril). La "contratación circular": el papel de la compra pública en la realización de una economía circular y la utilización eficiente de los recursos. Observatorio

(86) Idea defendida por Chinchilla. Véase en Chinchilla Marín, C. (2016). El derecho de la Unión Europea como freno a la huida del derecho administrativo. Revista de Administración Pública, 200, 361-383. https://doi.org/10.18042/cepc/rap.200.18. 
de Contratación Pública. http://www.obcp.es/index. php/opiniones/la-contratacion-circular-el-papelde-la-compra-publica-en-la-realizacion-de-unaeconomia.

Ponce, J. (2017). Las Agencias anticorrupción. Una propuesta de lista de comprobación en la calidad de su diseño normativo. Revista Internacional Transparencia e Integridad, 3.

Valcárcel, P. (2018). Apuesta por una revisión estratégica del modelo concesional: punto de partida y planteamientos de futuro. El Cronista del Estado Social y Democrático de Derecho, 74, 52-61. (6) 